\title{
The Politics of 'Unplanning' of Languages in Nepal
}

Ram Ashish Giri

\begin{abstract}
The elites, who have held power in Nepal since its inception in the eighteenth century, have deliberately ignored issues related to minority/ethnic languages in favour of the languages of their choice. While this 'unplanning' of languages has been responsible for the loss of scores of languages, it has helped the elites to achieve 'planned' linguistic edge over the speakers of other languages. This article outlines the sociopolitical and linguistic pretexts of the 'unplanning' of languages which favours Nepali and English, and explains why privileging of Nepali and English, essential though they are for education, employment and access to the world resources, has, in the existing situation, done more harm than good.
\end{abstract}

Key words: language planning, unplanning of languages, multilingualism, linguistic elitism, hegemony

\section{Introduction}

Nepal has been in the news lately for all the wrong reasons e.g.. This small Himalayan nation is in the grip of a socio-political transition because as the newest republic, it has embarked upon a debate about equitable policies in all spheres of life, and more importantly a debate in which people in the changed political atmosphere advocate for a new social and political order. The article discusses some of the issues that are shaping up the debate, in particular the language education policy debate; and by recapitulating historical and political pretexts, outlines how the dominant linguistic groups have conspiratorially ignored language issues to, what Alexander (2008) calls, 'entrench the domination of the powerful elites' (p.9)

The socio-political turmoil of the last two decades has brought the country to the verge of sociopolitical disharmony. As various tribal groups fight for their survival, their ethnicities and languages are likely to become one of the reasons for this division Therefore, Nepal, the Mecca of linguists for its vast linguistic resources is in all sorts of sociopolitical troubles; and the 'unplanning' of the very resources, i.e., its languages, is at the root of all this. By 'unplanning' of languages, I mean deliberate avoiding, delaying, and ignoring of language related issues, or imposition of hidden agendas (invisible planning?) in the pretentious contention of nationalism in order to create and promote language hegemony in favour of the languages of the dominant groups (Dua, 1994). Hegemony of language is defined as controlling the distribution of knowledge and learning of other languages except the elite languages. This, in practice, suppresses the development of other languages producing two negative consequences. Firstly it gives rise to an oversimplified generalisation of two languages, two

"This article is a revised version of the paper presented at the 18th International Congress of Linguists held in Seoul, South Korea, 21-26 July 2008 
peoples and two cultures. The two peoples mean the rulers, and the ruled; the two languages and cultures are the languages of the ruling elites (Brahmins and Kshetriyas, also spelt Chhetriyas or chhetris) and the languages and cultures of all others, the subjugated peoples. This article is based on the premise that languages and cultures are a resource, and like any other resources; they can be planned, developed and promoted.

In the first part of the article, I sketch the linguistic landscape of Nepal in which I talk about the historical and political reasons of why only one of over 100 languages and ethnicities has been dominant since the inception of the modern Nepal. I illustrate how by 'unplanning' its linguistic resources, the ruling elites have been responsible for the systematic extinction of minority and ethnic languages. I elucidate how they manipulate languages to serve their interest and how they use them to maintain the power structure, influence public opinion, channel political energies, and allocate economic resources for the education and promotion of the languages of their choice. As will become evident later, their approach marginalizes the speakers of other languages and unfairly disadvantages them in accessing sociopolitical and economic opportunities, resources and employment (Singh, 2007).

The article takes English as a case study. English in Nepal was imported historically for ideological and/ or political reasons, i.e., for using it as a linguistic edge to strengthen the socio-political superiority of the ruling elites (Stiller, 1993), and to reserve the access to world resources - economic and educational for themselves. In theory, it has been available to anyone and everyone through public education since the 1950s. In practice however, no rigorous planning of resources and pedagogic mechanism have been worked out for its effective delivery to the average people. For most of the six millions school goers, therefore, proficiency in the language remains underachieved. In this way, the 'unplanning' of English language education (ELE) has been a strategy of the elites to divide the broader Nepalese society. In the second part of the article, therefore, I situate English in the existing language education policy debate and discuss some of the issues, dilemmas and implications on the current language education policy debate in Nepal. In particular, I look into the historical, sociopolitical and educational pretexts of how English was adopted in the Nepalese education system and how social as well as educational institutions in the current system are structured either to preserve or perpetuate the interest of the elites at the expense of the larger interest of millions of others. I demonstrate how the conspiratorial 'unplanning' of its education has helped achieve the 'planned' results of English becoming a symbol of status, power and privileges, and facilitating the caste/class-based power structure. I argue that by 'unplanning' ELE for the average Nepalese people, the ruling elites have achieved results, which are visible, intended and planned.

\section{Linguistic Landscape of Nepal}

Predominantly a Hindu nation in the foothills of the Himalayas, Nepal has linguistically and culturally been overshadowed by two sociopolitical and economic giants, China and India. A diverse range of Tibeto-Burman and Indo-Aryan ethnicities interplay harmoniously in mountainous Nepal. Ethnographically, therefore, Nepal is a meeting point of the two great cultures blending into diversified cultural and linguistic richness. Nepal, however, has not been able to harness its huge cultural and linguistic resources. In fact, in the period from the establishment of the autocratic Rana-regime ${ }^{1}$ in the $19^{\text {th }}$ century to the Panchayatrule ${ }^{2}$ in the $20^{\text {th }}$ century, it adopted a policy that regards linguistic and cultural diversity as a threat rather than a resource.

As for the current language situation, all three types of language situations, monolingualism, bilingualism and multilingualism exist in Nepal. Languages, both dominant and non-dominant are constructed around the social life of the people of different ethnic backgrounds and they influence

\footnotetext{
1 A caste of rulers who set up a family rule and reigned Nepal 1848-1951

2 An authoritarian rule introduced in 1960
} 
their choice and use of languages. In this section I sketch the language landscape of Nepal in terms of the use of mother tongues or first languages, second languages and English and describe how their choice of language reflects on their socio-cultural backgrounds.

The ongoing Linguistic Survey of Nepal, launched in 2009, has thus far identified 104 languages (Kantipur, Jan. 29, 2009) with genetic affiliations to four different language families, namely, IndoEuropean (Indo-Aryan), Sino-Tibetan, AustroAsiatic and Dravidian. Indo-Aryan languages constitute the largest group of languages in terms of their speakers. Of all Indo-Aryan languages, 9 languages are spoken as the first languages by over three quarters of the population (76.07 per cent). Nepali, as the first language of nearly 50 percent of the population, is spoken in the hills and in far western mountains, some parts of the Terai and in urban areas. Other Indo-Aryan languages are mainly limited to the southern plains. Numerically, Indo-Aryan languages, therefore, overshadow all other languages. Most Indo-Aryan languages have literate traditions and share a well-developed writing system.

Sino-Tibetan languages constitute the largest number of languages, i.e., over 57 of them, spoken by about 18.4 percent of the total population which are spoken in different geographic pockets of mountains and hills. Kiranti group of languages, for example, is spoken in the eastern hills and mountains; whereas Magar, Thakali, Gurung and Sherpa languages are spoken in the central and western mountains and hills. Tibetan languages are spoken in the high mountainous areas such as Mugu, Dolpa, Mustang and Manang. Nepal Bhasha (also known as Newari) is spoken mainly in the Kathmandu valley. Of these languages, Rai and Limbu in the east, Magar in the central west and Nepal Bhasha in the Kathmandu Valley have been dominant in their respective regions.

Austric languages are spoken by some tribal groups in the eastern Nepal. Their introduction to Nepal, i.e., how and when they happen to be in Nepal is unknown. However, presence has been consistent and reported in all censuses. Their number in the latest census stands at 0.2 percent. Similarly, the speakers of the Dravidian languages are settlers in the eastern Nepal and have a genetic connection with some tribes in northern India (see also Yadava, 2005).

Urban and sub-urban areas are by and largeinhabited by the people of mixed-ethnicity. So, Nepali comes handy as a link language. The use of mother tongues gradually decreases in such areas even in family situations as the people live there longer. Families with inter-caste marriage and people returning to their villages after a considerable lapse of time tend to use Nepali in their villages because its use denotes being educated, economically well-to-do and socially superior. The choice of a second language, therefore, is not constrained by one's ethnicity but by economics and privileges. The people speaking over 57 Sino-Tibetan languages, for example, do not choose a second language from the same language family; but adopt Nepali as their second language conditioned by contact, peer pressure, employment, education and as the quotation below suggests, economic success

Maintaining the mother tongues whether within the indigenous area or outside of it, involves an extra effort, yet it brings no economic advantage. In fact, it may even be a hindrance to fluency and mastery of the prestigious national language. Thus mother tongue speakers of indigenous languages may feel compelled to abandon their mother tongues in order to succeed economically (S. Toba, I. Toba and Rai, 2005, p. 21).

Nepali is perceived to be instrumental as well as threatening. It is instrumental for its role in education and socio-economic development. As the language of education, administration and business, it has helped develop uniform and organised system of operation throughout the nation. However, its ever-growing importance is a threat which entrenches the already existing societal and class divisions even further. It also endangers the survival of local languages. The non-NFL speakers as a result of the linguistic domination have lost pride in their own languages, feel discriminated against, and 
as the quotation below suggests, have developed a tendency to neglect their languages in favour of Nepali:

As many of the indigenous languages were suppressed under the Rana regime and the Panchayat era which actively pursued "one nationone language" policy, indigenous people have come to consider their languages not only unsuitable for education and business, but also inferior to Nepali in general. Therefore, they try to improve their competence in Nepali rather than cultivating and preserving their own mother tongues (S. Toba, I. Toba and Rai 2005, p. 23).

As a consequence, a tendency in non-Nepali speakers is emerging in their language use, that is, language shift. There is a decreasing trend in the use of ethnic languages and increasing trend in the use of Nepali. Speakers of ethnic languages moving to urban areas for education and employment go through the transition of bilingualism with Nepali increasingly replacing their mother tongue. Similarly, there has been a sharp increase of Nepali speakers in the Terai (southern plain) lately due to the same reason.

\section{The Invisible Politics of 'Unplanning'}

The policy of 'unplanning', as discussed in the beginning of the article, may be attributed to a number of strategies or tactics. The ruling elites employ a number of tactics to appease the public but at the same time maintain the social structure and consolidate their position. A few of their tactics are discussed below:

\section{The policy making process}

Several authors have pointed out that the language policy making in Nepal is far from transparent. Pointing out the faults of the language policy formulation process, Lawoti (2004) and Manandhar (2002) suggest that on most occasions, the processes have been commandeered by a few people from the ruling elites. Language policy making is rarely seen as a multi-disciplinary process. Language related issues are not discussed openly and public opinions are seldom sought. Some elite linguists are tactfully chosen so that the outcomes of such a process help keep the current socio-political structure intact (Lawoti, 2004 and 2001; Sonntag, 2001 and 2003; Macfarlance, 1994).

\section{Language Cynicism}

The 1990-Constitution recognised Nepali as rashtra bhasha and other local languages as rashtriya bhasha (Part 1, Article 6). The literal translation of these two terms may be roughly 'language of the nation' and 'national languages'. To any person who knows some Nepali, the distinction between rashtra language and rashtriya languages is blurred as they roughly may mean the same thing. However, in practice, Nepali, the rashtra language gets all the privileges while other rashtriya languages are mainly left to the people who speak them without resources and support (Manadhar, 2002). After a fierce criticism from linguists and indigenous leaders, the dichotomy has been dropped from the Interim Constitution of Nepal 2007 (see for example, Part I, Article 1, sub-article 5). However, Nepali, remains as the most privileged and the only language of administration/business at all levels. Thus, by making merely a sketchy provision for the local indigenous languages and by not providing any significant directives or models of resource provision for their adequate preservation, maintenance, education and use, the new constitution too is based on wishful thinking without any practical relevance and is not expected to make any difference in the existing linguistic landscape (Giri, 2007)

\section{Avoidance}

There is a tendency in the concerned authorities (mainly comprising ruling elites) to avoid or ignore language related issues. The reports on and complains about language related issues are numerous. Despite repeated requests by the academia and the people concerned for actions (See Malla, 1983, for example), there have been no definitive courses of action to address their concerns. People, tired of the indifferent attitude of the authorities, either lose their interest or their motivation to pursue the matter any further or lose their patience (see Giri, 2009). 


\section{Complacency}

The authorities, when approached with a languagerelated issue, often promise to do the 'needful'. When they say that they will do the 'needful', it often means 'no need to take any action'. By accepting an application and in theory recording the grievance in their official 'registration logbook', the authorities take satisfaction that they have done the needful at their level. One other example of such complacency can be seen in the Interim Constitution of 2007. In the changed political context of 1990, for example, the political parties, which promised to review the ethnic and minority language and cultures issues, offered no significant initiatives except making a brief mention of the issue in the official documents. They take great satisfaction in merely allowing some communities to operate mother-tongue schools in their respective communities (Giri, 2009).

\section{Delaying}

As indicated earlier, the concerned authorities hold a language-related issue as long as they can without taking any action on it. An example of such a delaying tactics is the policy on Sanskrit. After a long debate over Sanskrit, which had been compulsory at the lower secondary level (Years 6-8), the Language Education Policy Recommendation Commission (1994), in which the memberships were mainly from the ruling elite (Lawoti, 2004), reported that students of this level could choose their mother tongue as a subject instead of compulsory Sanskrit. This optional replacement of Sanskrit with mothertongue, however, would go into effect for those entering the school system in 1994 (i.e., first graders in 1994). It would take six years for them to reach the stage where they have to choose between Sanskrit and ethnic languages (or mother tongues). This means that the policy would allow the authority six years to sort out the policy on Sanskrit (Sonntag, 2001).

\section{Discrepancy between Planning and Implementation}

There is a big discrepancy between what the authorities promise through their plans and proposals and what is actually delivered. This could be due to the fact that Nepal is a highly bureaucratic and centralised system. Most of the decision taken at the central level is rarely supported by carefully planned implementation strategies and needed skilled human resources at the local level. For most plans, therefore, as Kerr (1999) below notes, the local implementation capability and resourcing mechanisms are not considered:

Many plans are nothing but exercises in wishful thinking or even futility ... even carefully designed plans in education encounter implementation problems ... for the development of education takes place at the base of the system. Whatever decisions may have been taken at higher hierarchical levels, the key to success or failure of a given plan lies in the hands of local teachers, administrators, parents ... greater attention must be paid to implementation capability of the local level in the educational system, and to make sure that the community at the base of the system has the information and resources, and most important the commitment necessary for the successful implementation of educational development programmes (p. 232).

\section{Lack of political will}

Another example of unplanning can be seen in the lack of a political will or position on languages including the English language. There is a plethora of official documents reiterating the states' plan for effective and quality English language education (ELE) for all. In practice, however, there is no political consensus to ensure models of resource provision for achieving such a goal. As a result, there is not enough resource, both human and material, and support mechanism at the local level. Quality and effective ELE for all, thus, remains an allusion. The plans and proposal may simply be a bureaucratic tactic to appease some people rather than to improve its practices (Sonntag, 2001).

\section{The Debate}

If the news of the last few years is to be believed (see for example Kantipur, Gorthapatra, The Rising Nepal, Annapurna Post, The Himalaya Times, The Nepali Times, Himal Khabar Patrika; and 
ekantipur.com; Nepalnews.com; and Gorkhapatra. gov.np between August 2007 to December 2009); Nepal has already been broken into several states and sub-states, each one with a separate governing body. The Communist Party of Nepal (Maoists), for example, has divided the country along the ethnic line into eight states and five sub-states (the recent proposal from the Constitution Drafting Committee is of 14 states) (see ekantipur.com, Jan. 21, 2010). The Janatantrik Terai Liberation Front and other factions of the militants have announced their break away from the Nepal state and establishment of separate states in the southern plain. Similarly, Limbuwan, Khumbuwan and Tamuwan of the East have now their own states. Theoretically speaking, there are, thus, a number of states in different parts of the country. As discussed below, dividing a multilingual country like Nepal, where the societal mix is complex, is a political stunt and will not serve any practical purpose. What this signifies though is the fight or movement against the central authority which has not fulfilled their demand of selfdetermination. A political problem though it may seem, in the centre of the political frenzy, however, lies the socio-cultural and language problem. The militating ethnic organisations not only want political and economic equality, they also want the right to self-determination, self-governance and autonomy for all social groups, castes, cultural and language groups (Himal, 1 September 2007).

So, what is the language policy debate about? How is the Nepali language, so far the only official and official language, viewed in the debate? What are the implications of the debate for English language education? These are some the questions I attempt to address in this section.

Language policy is subservient of the national politics. In other words, linguistic change is a part of the political change of a nation. 'Unless there is a drastic change in the national politics both in terms of its form and its substance, the language policy of Nepal is not likely to change much' (Giri, 2009, p. 11) ). This somewhat cynical view held by many Nepalese people is not entirely incorrect. Like Nepali politics, language policy is evolving, unpredictable and controversial. It is evolving in the sense that a full-fledge debate about the status, role and use of the local, national and internatioonal languages has just begun. It is yet to gain its momentum as the present debate mainly centres around the politics and political structure of the state. However, what the language policy turns out to be depends largely on the outcome of the current political debate. The structure of the state, for example, will decide what structure of language education takes in the future. It is unpredictable at the moment in that it depends how the ethnicities and language groups are treated in the new constitution. Finally, it is controversial because different political blocks seem to have different thoughts about language policy, and a common approach to languages is hard to be agreed upon.

In the current language policy debate, there are three schools of thoughts emerging. The first one, advocated by people and parties associated with the left block of politics, is what is known as the nation-state system of governance. In this approach of federalism a group of people with common language, common culture and common religion have right to self-rule and therefore to a separate state. A nation, in this sense of the expression, is a federation of several states divided along the ethnic and language lines. These people believe that because the approach worked well in the past, it should work well in developing contexts now.

The second school of thought, proposed by the radical political groups, puts forward the case of state-nation approach to federalism. According to this thought, in the context of heterogeneous society and massive people movement and migration, nation-state approach to federalism is neither feasible nor practical. Therefore, the advocates of such a system, actually live in the past, or do so for a cheap political gain. In increasingly multi-ethnic, multicultural and multilingual countries like Nepal, only geographic states can be created in which people of all cultures, religions and languages have their separate identities ensured through the principles of co-existence, mutual respect and equitable governance. As for the ethnic and indigenous 
languages, they have sentimental or symbolic value. In today's world of globalisation and competition, local languages neither help nor provide any opportunity. People value their language because they attach them to their identity. So, they are dear to them. Apart from that the local languages do not have any instrumental significance. In fact, they may bring, as discussed in the final section of the article, negative complexes.

The third school of thought, however, advocates for more inclusive politics with concession of autonomy to communities, which are concentrated in certain geographic regions and are capable of making their own socio-cultural and language education decisions. This calls for an educational solution to a political problem. The ethnic and indigenous people want their languages and cultures to be preserved which can be done by allowing them to educate their children in their language up to certain level. The system is recommended by the Nepali academia and language experts as the most appropriate line of thinking in the given circumstances (see also Lawoti, 2004; Rana, 2006). This approach is formed on the three-language policy in which the local language, national lingua franca, and English as an international language have appropriate places allocated and their roles defined. Academics and language experts recommend.

\section{English in the Language Policy Debate}

The imposition of Nepali and Nepali belief systems, as discussed the foregone section, has been a major factor in the recent political turmoil (Onesto, 2005). The inequitable distribution of English language education (ELE) has further complicated the situation. During the Rana oligarchy English was imported, and adopted as an advantage in favour of the ruling elites (Vir, 1988).

The idea of language hegemony was further strengthened with the introduction of English to education in the 1950s when Nepal embarked on planning formal education for the first time. The Government of Nepal, appointed Dr. Hugh B. Wood, a US Fulbright scholar in India, advisor to Nepal National Educational Planning Commission
(NNEPC) in 1954 the report of which has had overarching influence on education policy and which became the foundation for language education policy in Nepal. In fact, the Commission's legacy continues in the construction, deconstruction and reconstruction of Nepal's language policy (Awasthi, 2004)

Awasthi (2009, in press), and Cadell (2002) suggest that Wood was heavily influenced by Lord Thomas B. Macaulay, Chairman of the Governor-General's Committee on Education in India in the 1830 s. The minutes he wrote during his chairmanship, popularly known as the Macaulay Minutes, are regarded as a historic document on Indian education and the foundation of the Anglicisation of education system in India.

Macaulay's approach to education was what later came to be known as the 'Downward Filtration Model' the purpose of which was to filter, select and educate a class of Indians who could function as interpreters between the British rulers and the millions of Indians they governed - a class of persons Indian in blood and colour but English in taste, opinions, in morals and intellect (Edwards, 1967). Wood's 'Linguistic Restrictionism (restricting education and use of multiple languages in public domains) theory' and the concept of multilingualism reduction have its direct roots in the Macaulay's model of education. Wood as the architect of the NNEPC report orchestrated the report to shape the Nepalese language education policy. Therefore, the concept of monolingual Nepal was a non-Nepali ideology imposed on it by, as Awasthi (2004) below suggests, someone with neo-colonial attitude:

... the reduction of multilingualism was not an indigenous construct of Nepal. Linguistic restrictionism was an alien concept for the people and polity, and was an importation from the West. The concept of reductionism grew during the British Raj in India and flourished [in Nepal] after the NNEPC report (Awasthi, 2004. p. 34).

The politics of English as a global language is primarily local because while it has to cater to the global demand of the Nepalese people, it must also 
meet the local socio-political conditions. That is to say, the status and role of English must appropriately be situated in the local language policy debate. However, most of the debate on language policy in Nepal centres around the local languages and no debate seems to occur around English. Whatever debate takes place in relation to the language is limited to curricular and pedagogic matters and distribution of ELE facilities (Kansakar, 2009).

There is no doubt that English has established itself as a language of power today, but more importantly, it has become powerful because it has been used as a tool as well as a resource for social mobility, linguistic superiority and educational and economic benefits. This unspoken privileging of the language is a deliberate attempt to create a further division in already divided Nepalese society. The language has been used as an instrument by the elites to maintain their superiority (Stiller, 1993). The role this language has played in the community has, therefore, been controversial, and in the absence of a clear state policy for its education, the language has done more harm than good. It is not only creating a socio-cultural and linguistic chaos, it also results in emotional and social displacements which together may be termed as cultural anarchism (Giri, 2009).

Furthermore, despite the rhetorical provisions in the new constitution, Nepal appears to be working with the fallacy that monolingual governments are more efficient than multilingual governments; and that multilingualism always divides and monolingualism always unites. As a consequence, instead of producing constructive policy, the fallacy has created problems and counterproductive issues.

\section{The Results of the invisible policy of unplanning}

Declining parity of esteem of ethnic languages and falling mother-tongue education

As discussed above, the 'unplanning' of languages and unspoken privileging of Nepali and English have produced a number of undesirable consequences. One of such consequences is declining parity of esteem of ethnic and indigenous languages. Though the current policy allows administrative sanction and limited economic support of certain level for the education of some ethnic languages, there is no statute to protect and support their legal status. With the diminishing educational and economic value, the people of young generation do not value their languages at all. As a result, these language communities are gradually losing their speakers.

For the Indigenous people, mother tongues and their education have been their priority because 'it is only by knowing our language; we can make progress in all fields of life' (says an ethnic language teacher interviewed in 2007). However, this is simply a rhetorical statement. The existing mother tongue schools are experiencing a decline of students because, as discussed elsewhere in the article, they do not see any practical relevance of knowing their language. In recent years, a significant amount of interest has been shown especially by the people of tribal groups to educate their children in their local language, i.e., mother tongue. A dozen of mothertongue education schools are in operation in various parts of the country (Yadava, 2005). This supposedly promotes their language nationally. However, the ethnic groups themselves point out the fact that the knowledge of the local language does not have the same value in employment, trade, media and education as English or Nepali. Inclusion of English (and Nepali) in mother tongue education, therefore, has been viewed necessary without them education in the ethnic languages alone is neither possible nor practicable (Eagle, 2000).

Esteem of ethnic languages is declining at all levels and in all spheres of socio-politics. The main reason for this is the attitude of the Nepali speaking elites. The majority of the Nepali as the first language (NFL) speakers, for example, is monolingual. As it is the language of administration, education, media, business and employment, the NFL speaker neither see any rationale nor do they feel any need to learn other local languages. They have, therefore, no knowledge and regard for the indigenous languages. In fact, they often develop some sort of unfriendly outlook towards and superiority complex over the non-NFL speakers. The Nepali speaking elites, therefore, rarely see the importance of maintaining or 
preserving local languages. They consider linguistic and cultural diversity as a hindrance and something that prevents rather than aid the development of nationalism. The non-NFL speakers, on the other hand, as a result of the century old linguistic domination and privileging of Nepali have lost pride in their language, feel discriminated against, and, as S. Toba, I. Toba and Rai (2005) indicated above, have developed a tendency to neglect their languages in favour of Nepali.

The following two real stories illustrate the issue further.

Like millions of Nepalese people, I grew up in a bilingual situation. At home I spoke Maithili, a local ethnic tongue, but at school and neighbourhood, I spoke Nepali. From the very childhood, I was led to believe that 'people are born equal, but some people are more equal than others' and language was an important factor in it. Very soon I realised that speakers of Nepali were different and that those who spoke Nepali were treated as 'superior', 'educationally brighter', 'more talented' and 'more knowledgeable'. And I realised that Maithili was less valuable compared to Nepali, and it served no practical purposes other than communication with my parents and relatives. It neither helped me socialise with my fellow Nepali speaking students nor did it provide me with the same opportunity, access, knowledge and ability as Nepali did.

The linguistic and cultural divide was more pronounced in the cities than in the villages. When I moved to a city for my higher education, I realised that there was yet another level, another circle and another community of people with bigger and larger access and opportunity for education and employment. And English was their language. In this way, I chose Nepali and English for educational and economic opportunity and social benefits, and in the want of becoming a part of broader and wider social and educational network, I abandoned Maithili.

\section{Sadly, my story is not unique}

In June 2008 (see Rork, 14 June 2008), a foreign linguist in Kathmandu was stunned to hear a Newar mother who said she did not talk Newari with her husband in the presence of her children lest they might learn it.

"Why is that so?" asked the linguist.

The mother replied, "Well, it's rather nice thing to learn your own language but you know my children will lag behind. English as an international language and Nepali as a communicative language are just fine; another language will make them dull."

The stories above illustrate how millions of the Nepalese people view their languages and why they abandon them. The elites consider Nepali as a superior language and, as previously discussed, employ all political and educational means to perpetuate its dominance. As a result, the non-NFL speakers develop an inferiority mindset towards their own languages. The speakers of dominant languages persevere overtones of dominance because their language background ensures their participation in the national life. The speakers of other languages, on the other hand, are looked down upon, despised and often surpassed in the process of socio-economic and political development.

\section{Non-integration of the speakers speaking other languages}

Tensions among different language/ethnic communities are too a result of the language policy. One of the common causes of such tensions is the official stance, either in theory or in practice, about the mainstream languages. When people want to be integrated like items in a salad bowl, they are made to assimilate like ingredients in a melting pot causing insecurity, injustice and inequality in the ethnic/minority communities. The integration policy aimed at social transformation is creating tension because speakers of ethnic/minority languages are discriminated against those of mainstream languages such as Nepali and English. Similarly, the goal of making Nepali a language of all Nepalese people remains underachieved as it has not yet become a common language for many indigenous ethnicities. As a result, those who do not speak the mainstream languages do not integrate well in the mainstream life. 


\section{Policy Contradiction}

The policy regarding languages and how they are put to practice are also a source of tensions. There is a contradiction between the official policy or official position regarding languages, and the actual linguistic practice. For example, the current sociopolitical provisions encourage only Nepali to be used in public domains restricting minority languages to limited social and private domains (ekantipur. com, 15 Nov. 2009). Despite multilingual language policy rhetoric in the current linguistic and political discourses, hegemonic control of the elite languages persists and consequently, Nepali and English dominate the practice of all other languages. An example of such a contradiction can be seen in the recent decision of the government to use English, alongside Nepali, rather than local languages, in the citizenship card. This decision does not benefit the vast majority of the Nepalese people who are illiterate and will never know what is written in English. This contradiction in practice consolidates the adverse attitude the speakers of other languages have towards their languages.

So far as the English language is concerned, there is a contradiction between the political aims and economic aims of ELE in Nepal. The academics are recommending a compromise between the aims by suggesting that English should not be taught until after the elementary level of education as in the lack of adequate resources and teaching conditions, the ELE goals remain underachieved. Introducing it at a later stage of education will enable the state to be better prepared in terms of resources - both human and material, infrastructure and teaching conditions. The state, however, in the name of social equity in education, has introduced it in Year 1 , which without adequate plans and resources is merely a ritualistic exercise.

\section{Politicising language policy}

As discussed in the foregone sections, linguistic elitism helps achieve hegemonic control over scores of other ethnic and minority languages. This in practice controls the distribution of learning, usage and resource facilities. In order to maintain the existing linguistic structure, language policy making processes are highly politicised. Despite promised autonomy of policy making, language policy has been subservient of the ruling political parties which exert their ideological and political influence on the policy-making process as well as the product. As for the policy of the political parties, language policy is like political manifestos, which manipulates, perpetuates and promotes their linguistic interest. The pro-Nepali politics comes from the people of the parbatiya group who promote Nepali as the language of the pahades (the hill people). The promotion of Nepali as the dominant language, therefore, means the extension of the dominance of the parbatiya community on all Nepalese people, which then paves way for Nepali language and culture to be placed above all others.

There is thus a lack of political will and lack of a consensus among the political actors and ruling elites to distance themselves from the narrow ideological/political conscience and work for a broader interest of all sections of the population.

Aligning languages in term of their socio-political and economic relevance

One other consequence of unplanning is the way in which the indigenous/community languages are treated, prioritised or aligned for education, use and preservation. There is a tendency to align languages in terms of socio-political rationale. For example, languages of socio-politically dominant communities have been selected and given space in media, education and to limited extent public domains leaving at least several dozens of languages in their own fate. The authorities and social elites, therefore, channel away resources and energies into learning of these preferred languages instead of researching, investing, and maintaining the vast linguistic resources for their linguistic, cultural and human potentials.

\section{English: One Language - Multiple Literacy}

As indicated earlier, the lack of planning has created confusion in the status and role of English. There is, for example, a contradiction between how the elites view English and what the common people expect 
of it. The ruling elites are content with the current ELE arrangement because the discriminatory access to English helps maintain their status quo (Kerr, 1999). The academics have always recommended that English cannot and should not be compulsory for all at all levels of education (Kansakar, 2009; Davies, 1984; Malla, 1977). The common people, on the other hand, inspired by the current situation, expect that English must be for all, available at all levels and for all sections of the population. For them, English is a 'social capital', and like all other capitals, it must be carefully planned and 'fairly distributed'.

The status and role of English, irrefutable they may be in the Nepalese contexts, are far from clear. It is not clear, for example, how a uniform teaching and learning policy can address the complex population diversity and their diversified needs of English. Based on geography and the different economic activities people are engaged in, there are surely different needs requiring different levels of English proficiency for different types of populations. It needs to be ascertained who needs what type and level of English and how this is to be accomplished. However, the current debate only reveals that the place of English in Nepal is unassailable and it must form an important part of any educational package. What it does not address is the fact that different sections of the Nepalese population require different types/levels of English.

English language education, therefore, faces the dilemmas of social equity, social division and equitable practice. Academics and educational experts, for example, believe that ELE has to be based on the reality of the situation, and taking into account the fact that different sections of populations need different types and different levels of English, and that while English is 'second language in urban areas', it is the third or even fourth language in the rural and remote areas of Nepal, the English language must be treated differently in different parts of the country. This means that there has to be different literacy targets for different types of population. However, fair though it sounds, it creates a policy contradiction as it denies the same level of opportunity and excess to all.

\section{Conclusion}

Languages in Nepal have been conspiratorially manipulated to serve the interest of the dominant groups of the society since the very formation of the state in the eighteenth century. The elites have deliberately ignored the issues related with the minority and ethnic languages for socio-political reasons. The 'unplanning of languages' has helped them have a linguistic advantage and competitive edge over others, and better access to education employment and economic success. It has also helped them maintain linguistic dominance. The unplanning has also created a great deal of confusion. English language education in Nepal is, for example, at the crossroads. Its hegemonic past, its deteriorating standards in public education, its divisive role in the community, and uncertainty of its future on the one hand, and on the other its ever growing demand in all socio-economic and developmental domains is creating a policy contradictions.

What is needed is a policy framework, which recognises languages as a national resource not only in theory but in practice also. What is also needed a definitive course of action to develop a policy that, recognising their socio-economic and educational role in development, adequately accords a place for Nepali and English along with other local languages. Therefore, an inclusive language policy which is progressive in its principle and accommodative in its approach is the way forward.

Ram Ashish Giri is a Reader in the Faculty of Education, Tribhuvan University, Nepal. He has master's degrees from Nepal and USA and a doctoral degree from Australia, Presently, he teaches at Monash University, Melbourne. He has written textbooks and book chapters and has published articles in the national and international journals. His research interests include English language education, language testing and language education policy. He has presented his research reports at the international conferences in the UK, Pakistan, South Korea, Australia and Nepal. He was the founding secretary of NELTA and also served as its general secretary and later vice-president. Currently, he is a reviewer for Journal of NELTA. 


\section{References}

Alexander, N. (2004). The politics of language planning in post-apartheid South Africa. Language Problems and Language Planning, 28(2), 113-130.

Alexander, N. (2008). Proper use of mother-tongue the way forward. Feature Article Cape Times, April 21 2008 (p. 9).

Awasthi, L. (2004). Exploring monolingual school practices in multilingual Nepal: $\mathrm{PhD}$ Thesis Copenhagen, Denmark: Danish University of Education.

Awasthi, L. (2009). (in press). Importation of ideologies: from Macaulay to Wood commission report'. In Farrell, L., Singh, U.N. and Giri, R.A. (Eds.) English Language Education in South Asia: From Policy to Pedagogy. India: Cambridge University Press.

Caddell, M. (2002). Onward looking eyes: visions of schooling, development and the state of Nepal. $\mathrm{PhD}$ Thesis. Edinburgh, UK: University of Edinburgh.

Davies, A., Maclean, A. and Glendinning, E. M. (1984). Report of the survey of English language teaching in Nepal. Kathmandu, Nepal: The British Council/ ODA and HMG/N Ministry of Education and Culture..

Dua, H.R. (1994). Hegemony of English. Mysore: Yashodha Publications.

Eagle, S. (2000). The language situation in Nepal. In Baldauf, R. B. and Kaplan, R. B. (Eds.) Language planning in Nepal, Taiwan and Sweden. Sydney: Multilingual Matters Ltd

Edwards, M. (1967). British India 1772-1947. New Delhi: Rupa Press.

Ekantipur.com. (2009). News. Retrieved on 29th Jan. 2009 from ekantipur.com

Ekantipur.com. (2010). News. Retrieved on $21^{\text {st }}$ Jan. 2010 From ekantipur.com

Farrell, L., Singh, U.N. and Giri, R.A. (Eds.)(2009, in press). English language education in South Asia: from policy to pedagogy. India: Cambridge University Press.

Giri, R. A. (2007). The power and price of English. In
Farrell, L. and Fenwick, T. (Eds.) Educating the global workforce. London: Routledge.

Giri, R.A. (2009). Cultural anarchism: the consequences of privileging languages in Nepal. Journal of Multilingual and Multicultural Development, Fall 2009. 1-14

Himal. (2007). Forum. Himal khabar patrika. Vernacular Nepali Fortnightly, Sept. 1

Kansakar, T.R. (2009 in press). The theory, practice and pedagogy of English as a foreign language in Nepal. In Farrell, L., Singh, U.N. and Giri, R.A. (Eds.) English language education in South Asia: from policy to pedagogy India: Cambridge University Press.

Kerr, R. F. (1999). Planning and practice: factors impacting on the development of initial education in Nepal with special reference to English language teaching. $\mathrm{PhD}$ Thesis. Melbourne: Victoria University,

Lawoti, M. (2004). The constitution as the source of exclusion. Kathmandu: Nepal Bhasha Academy.

Malla, K. P. (1968). The lure of English. In Malla, K. P. (Ed.)_The road to nowhere.. Kathmandu: The Shaja Publications.

Malla, K. P. (1979). The road to nowhere, Kathmandu: Sajha Prakashan,

Malla, K. P. (1983). River-names of the Nepal valley: A study in cultural annexation. Contributions to Nepalese Studies 10(2): 57-68.

Manandhar, R. (2002). National language or language of the nation, what's it? Feature Article. The Kathmandu Post, 21 February 2002.

NEC (1992). Report of the National Education Commission. Kathmandu, National Education Commission Nepal. Kathmandu: HMG/Nepal.

Nepalnews.com. (2007). Maoists decide to divide country into 13 units [news]. Retrieved on 16th Aug 2007 from http://www.nepalnews.com.

Nepalnews.com. (2009). First linguistic survey starts (news). Retrieved on 6th Mar. 2009 from http:// www.nepalnews.com.

Onesto, L. (2005) Dispatches from the people's war in Nepal. London: Pluto Press 
Rana, B.K. (2006). Analysis of some endangered languages. England: Foundation of Endangered Languages

Roak, H. (2007). Multilingual world. Feature article. The Kathmandu Post 14 June 2008. Accessed at www. kantipuronline.com

Singh, J. (2007) [Front Page Feature News] in Kantipur, A Vernacular Nepali Daily. Retrieved on 21 Sept. 2007 from www.kantipuronline.com

Sonntag, S. K. (2001). The Politics of determining criteria for the language of education in Nepal. In Fleiner,T., Nelde, P. H. and Turi, J. (Eds.). Droit et langue(s) d'enseignment: Law and language(s) of education. Bale: Helbing and Lichtenhahn

Stiller, L. F. (1993). Nepal: growth of a nation. Kathmandu, Nepal: Human Resource Development Research Centre.
Toba, S. (1992). Language issues in Nepal. Kathmandu: Samdan Books \& Stationers.

Toba, S., Toba I. and Rai, N.K. (2005). Diversity and endangerment of languages in Nepal. Kathmandu: UNESCO Nepal. Working Paper 7.

Vir, D. (1998). Education and polity in Nepal: an Asian experiment. New Delhi: Northern Book Centre.

Yadava, Y. (2005). The politics of language planning in Nepal's multilingual contexts: its implications for the Terai. Paper presented to the conference on Nepal Terai: context and possibilities. 10-11 March. Kathmandu: B.P. Koirala India-Nepal Foundation. 